\title{
Leave Truth Alone: on Deflationism and
}

\author{
Contextualism
}

\section{Daniel Whiting}

The definitive version of this article is published in European Journal of Philosophy by Wiley-Blackwell, and will be available at

\section{http://www.interscience.wiley.com/}

\section{Deflationism}

According to deflationary accounts of truth, of the sort Paul Horwich defends, ${ }^{1}$ grasp of the concept of truth consists in nothing more than a disposition to accept a priori (non-paradoxical) instances of the schema:

(DS) It is true that $p$ if and only if $p$ According to Horwich, the equivalences embodied in (DS), or a suitable variant, exhaust the content of the notion of truth and thereby tells us all there is to know about truth (1990: 36).

Deflationists typically supplement this account with a story about the point of having such a semantically scant expression as 'is true' in the language, according to which it allows one to endorse propositions that one is not in a position to state. Suppose, for example, that one wants to express agreement with everything Sophie says. One (unfeasible) option would be to produce a list:

(1) If Sophie says that the pygmy shrew is Britain's smallest mammal, then the pygmy shrew is Britain's smallest mammal; if Sophie says 
that the white-toothed shrew is Britain's smallest mammal, then the white-toothed shrew is Britain's smallest mammal; if Sophie says that the white-toothed shrew is endangered, then the white-toothed shrew is endangered; ... and so on indefinitely.

Alternatively, the truth-predicate allows one to formulate:

(2) Everything Sophie says is true.

Suppose that Sophie says that the pygmy shrew is Britain's smallest mammal. From this, plus (2) and one's grasp of (DS), one can infer:

(3) The pygmy shrew is Britain's smallest mammal.

As Horwich says, 'it is from precisely this inferential property that propositions involving truth derive their utility' (1990: 2-3). Having noted this, however, there is nothing more of substance to say about the nature of truth.

According to Charles Travis, 'deflationism is a mistake'. In his view, 'there is much to say about what truth is', much more than deflationism allows (1996: 453, 451; cf. 2000: 233). His argument in support of this claim is based on contextualism. In the next section, I shall sketch Travis's version of contextualism. Having done so, I shall outline his stated reasons - doing my best to fill in various gaps — for thinking that it undermines deflationism.

One response to Travis's challenge that a proponent of deflationism might make is to reject contextualism (see Simmons 1997). ${ }^{2}$ Rather than pursue this strategy, I shall argue that there is nothing in contextualism that deflationists need deny, that Travis's attempt to 'inflate' the notion of truth by appeal to contextualism is unsuccessful. 
Note that, while I am broadly sympathetic to deflationism, I am seeking neither to offer a cogent argument for it nor to provide a fully comprehensive defence of it. The aim is only to defend deflationism against this particular attack. ${ }^{3}$

\section{Contextualism}

According to contextualism, as Travis formulates it, It is intrinsically part of what expressions of (say) English mean that any English (or whatever) sentence may, on one speaking of it or another, have any of indefinitely many truth conditions, and that any English (or whatever) expression may, meaning what it does, make any of many different contributions to truth conditions of wholes in which it figures as a part. (1997: 87)

One can reformulate contextualism as the view that any given sentence might, on different occasions of use, express one of any number of different propositions, all compatible with its possessing the meaning it does (where this does not result from indexicality and the like). So, according to contextualism, the meaning of an expression only partially determines what is expressed in its utterance. What more is required for a proposition with certain truth-conditions to be expressed? For Travis, the additional input is provided by 'the circumstances of the speaking', 'the character of the occasion on which given words were used' (1996: 458). In light of the particular circumstances, there are things one may 'rightly expect of giving a description; ways one has a right to expect oneself thereby to be enabled to deal with the surroundings one then confronts' (2006: 30). Facts about such matters-which are not arcane but in principle discernible by anyone in the relevant situation and familiar with the kinds of needs and interests creatures like ourselves have-contribute to determining the truth-conditions of what is expressed on the occasion of utterance.

To make this more concrete, consider: ${ }^{4}$ 
(4) There is milk in the fridge.

Suppose that David utters (4) and Kelly, on opening the fridge, finds a small puddle of milk on a shelf. Whether she should evaluate what David said in uttering (4) as true or false - and so the truth-condition of what he said on that occasion, or the proposition he expressed - arguably depends on the circumstances. For example, if David offered (4) as an answer to a question about breakfast supplies, Kelly should reasonably expect to find a sufficient amount of suitably packaged milk — in which case what David said in uttering (4) is true if and only if the fridge contains a sufficient amount of suitably-packaged milk (which is to say, if and only if there is milk is in the fridge, so understood). In this situation, David would have spoken falsely. In contrast, if David offered (4) as an answer to a question about the cleanliness of the fridge, Kelly should reasonably expect to find spilled milk-in which case what David said in uttering (4) is true if and only if the fridge contains spilled milk (which is to say, if and only if there is milk is in the fridge, so understood). In such a situation, David would have spoken truly. Insofar as (4) is not distinctive in any relevant way, we are supposedly justified in generalising from this particular case and concluding that context-sensitivity is ubiquitous.

Needless to say, while reflection on such cases might speak in favour of contextualism, it hardly forces it upon us. Accordingly, Travis provides additional considerations, inspired by Wittgenstein's reflections on rule-following, ${ }^{5}$ intended to show, not simply that circumstances can play a role in determining what is expressed in an utterance, but that they must:

A signpost admits of interpretations. On the highway's edge is a blue sign with an arrow pointing right $[\ldots]$ The blue indicates the motorway. The arrow indicates that one turns right to get on it. But should I turn right, immediately, plowing through a fence, and then a field? Or should I go on to the next little service road and then turn 
right? Should I turn right and then reverse direction? Or should I wait for one of those recognizable motorway entrances, veer onto it (no sharp turns), and carry on? [...]

These are all ways someone might understand the sign. (2006:114)

Faced with this, one might despair, with Wittgenstein's interlocutor, that 'no course of action could be determined by a rule, because every course of action can be made out to accord with a rule’ (1958: §201). In contrast, Travis’s response is that the circumstances — and in particular the purpose of the sign — determines that a certain understanding is called for. If such considerations are 'acknowledged as actually deciding [...] what a signpost says, or what a rule says to do [...] then rules may, in fact, say and tell us what to do. If we disallow this role for the [context], then it hard to see how a rule could so much as say what to do' (2006: 118).

The line of thought appears to be as follows. That a sign admits of different understandings - as saying various things — seems to threaten the idea that there is anything that counts as understanding it — that it says anything — at all. Fortunately, context comes to the rescue by determining that it should be understood in a certain way - as saying one of these things. Thus, to hold on to the thought that subjects can so much as say things in using language, or understand what is thereby said, one must accept contextualism.

No doubt there are many things one might challenge at this point - the intuitions about (4)'s variation in truth-conditions, for example, or the inference from the particular case to what can be said of linguistic expressions in general, or the cogency of the Wittgensteinian argument. I shall set these qualms aside. The present concern lies not with the reasons given in favour of contextualism, but with the view's consequences.

\section{A dilemma for deflationism}


Contextualism, Travis claims, 'exposes a side of truth which deflationism misses' (1996: 466); it is 'a view of representation that a [deflationary] view of truth' does not 'fit' (2006: 197). One might be tempted to think that there is a quick argument against deflationism that takes contextualism as a premise. For any sentence of the form 'It is true that $p^{\prime}$, what would be expressed by it on one occasion might be true, while what would be expressed by it on another occasion might be false. This, surely, is to say that there are different understandings of truth. If so, there will be something substantive to say about these different understandings, which takes us beyond deflationism.

In reply, the deflationist will simply point out that what would be expressed by 'It is true that $p$ ' on an occasion would be true if, and only if, what would be expressed on that occasion by ' $p$ ' would be true. Hence, our different understandings of 'It is true that $p$ ' uttered in different circumstances go hand in hand with, are equivalent to, different understandings of ' $p$ '. It therefore remains to be shown that, so far as contextualism goes, there is anything in what truth is that is not captured by the instances of (DS), that our grasp of the concept of truth exceeds our disposition to infer according to that schema.

Since there is no quick argument from contextualism to a rejection of deflationism, what is the basis of Travis's hostility? His initial complaint is that deflationism says nothing 'about what it would be for words $[\ldots]$ to state truth'. In an effort to fill this lacuna, Travis considers a candidate explanation, according to which for words to be true is (nothing more than) for them to express a proposition that is true $[\ldots]$ Once it has been determined which, if any, proposition words expressed (or would express), it has been determined when they would be true: when that proposition would be true. (1996: 452-3) 
Crucially, as Travis points out, deflationism requires that 'whatever determines which proposition words expressed [...] does not depend on what it is for words, or anything, to be true' (1996: 453). That is, deflationism is committed to its being possible to explain what it is for words to express a proposition without making reference to the notion of truth (except in its role as a tool of generalisation). If such appeal were necessary, there would be more to truth — the concept of truth would have a more substantive, explanatory role to play—-than deflationism allows.

Travis proceeds to object that the explanation given above rests on the assumption that — indexicality and the like aside — which proposition is expressed in an utterance of certain words 'is determined by what they mean. Part of their meaning what they do is that $[\ldots]$ there is a particular proposition which is the one they would express' (1996: 453). At this point, unsurprisingly, Travis wheels in contextualism, reminding us that one and the same sentence, with the same meaning, might on different occasions of utterance, express different propositions. Hence, Travis concludes, since we have reason to accept contextualism, we must reject deflationism. It must be said that Travis's argument is, as stated, rather opaque. Granting that the deflationist is required to say something about how words state truth, why is the deflationist's account of truth-stating, which Travis proffers, so much as ostensibly committed to the denial of contextualism? On that account, recall, 'for words to be true is (nothing more than) for them to express a proposition that is true'. It is entirely possible to read this, in line with contextualism, as, 'for words on an occasion of utterance to be true is (nothing more than) for them on that occasion to express a proposition that is true'. It is simply an open question whether 'words' here picks out types or situationally-embedded tokens, and it is not obvious why Travis thinks that deflationism must read it in a way that conflicts with contextualism. 
Travis seems to find support for his accusation in the deflationist's reliance on the equivalence schema's doing all the explanatory work with respect to truth. That schema, he says, only relates 'descriptions (individuated somehow) for words to give of things' with 'the world thus described'; it is 'silent' on how circumstances bear on what those descriptions express in a given context (1996: 459; cf. 2000: 232).

Deflationism seems to assume that there is a one-to-one correlation between any particular sentences and a worldly state of affairs (whose obtaining is the condition of the truth of that sentence).

This, however, is a serious misrepresentation of deflationism. Consider an instance of the equivalence schema:

(DS1) It is true that the pygmy shrew is Britain's smallest mammal if and only if the pygmy shrew is Britain's smallest mammal.

The words as they occur on the left-hand side, just as much as those on the right, are used not mentioned; that is, they are to be viewed as uttered on a particular occasion and hence as already understood in the appropriate way. The phrase, 'that the pygmy shrew is Britain's smallest mammal' is thus understood as, given the circumstances, naming a particular proposition, the same proposition expressed on this occasion by the words on the right-hand side, one of the many that those very same words might on various occasions be used to express. Hence, the deflationist does not need to bridge a gap between the 'mere description' on the left-hand side and the world as described on the right-hand side, since the left-hand side is already conceived as expressing a particular proposition; the circumstances have already made their contribution. ${ }^{6}$

Travis's parenthetical qualification that the description on the left-hand side of any instance of (DS) is 'individuated somehow' might allow him to dodge the charge 
of misrepresenting deflationism, since it allows for the idea that the relevant description is individuated not merely as a certain expression bearing a particular meaning but as an expression uttered on a given occasion and understood in light of the circumstances. In that case, however, he lacks grounds for his complaint that instances of the equivalence schema neglect the context-dependence of what is expressed by words.

Evidently, we must do more digging to unearth an argument as to why contextualism 'departs' from deflationism. I think one can best reconstruct Travis's reasoning as presenting deflationism with a dilemma. Grant, with Travis, that deflationism must have something to say, not merely about what it is for propositions to be true, but in addition about what it is for words to express such propositions. On the one hand, the deflationist might say that for words to state truth is just for there to be some one proposition that those words, meaning what they do, express when uttered, where the truth of that proposition is explained in the usual deflationary way. Setting aside worries as to whether one can adequately characterise linguistic meaning or what it is for an expression to express a proposition without recourse to the notion of truth, ${ }^{7}$ contextualism anyway shows this account to be inadequate. For any given expression, there are indefinitely many propositions, each with different truthconditions, that might be expressed by one and the same expression, all compatible with its meaning what it does. However, if the deflationist accepts the contextualist perspective, she throws herself onto the second horn of the dilemma-in saying what it is for words to state truth, in a way compatible with contextualism, she must appeal to a notion of truth more substantive than that recognised by deflationism.

I shall not here comment on the first horn of the dilemma. It is certainly true that some deflationists hold that, for any (non-indexical, etc) sentence, the meanings 
of its constituents and how they are combined wholly determine that it expresses a particular proposition, with particular truth-conditions, when uttered (see Horwich 2005: 59-60). And I shall grant, with Travis, that contextualism shows this view to be false. Instead, I shall focus on the second horn of the dilemma and the issue of why the deflationist cannot tell a story about the role circumstances play in determining how words state truths without smuggling in an inflated notion of truth.

\section{$4 \quad$ Inflated demands}

Travis maintains that in recognising the role that circumstances play in determining what proposition is expressed on a given occasion - and so what, if any, truth is stated - one must forgo deflationism. But it remains unclear why. Surely, the deflationist can allow that any given expression, meaning what it does, might, depending on the circumstances, express any of an indefinite number of propositions. Her claim is only that, whatever proposition is expressed, the conditions of its truth can be explained in the deflationary way.

Travis's suggestion is that it is specifically in explaining how circumstances come to bear on an utterance, and thereby what is expressed in it, that one will have to make reference to what truth is. Since this will be a substantive explanation, truth will have to be a substantive notion, contrary to deflationism. As Travis puts it, 'What truth is makes circumstances matter as they do to what, in them, would be said in words with given meanings' (2000: 233).

It remains to be shown, however, that one can only explain the bearing of circumstance by recourse to a notion of truth. Indeed, when first outlining contextualism above - and following Travis - I cashed out the role of context in determining what proposition is expressed in uttering certain words bearing particular 
meanings in terms of what one may reasonably expect of a description, specifically concerning how it might enable one to deal with one's surroundings, given the situation. That explanation made no appeal to a notion of truth of the sort deflationists renounce. While it no doubt needs more unpacking, it is far from obvious that this would have to involve a substantive conception of truth that goes beyond what deflationism captures.

Travis seems confident, however, that, appearances notwithstanding, explaining how circumstances bear on our understanding of what is expressed in an utterance will inevitably draw on an 'inflated' notion of truth:

Truth depends on what words mean, the way the world is, and further factors: aspects of the circumstances in which words were produced. Whether, and how, any given such factor matters to the truth of particular words must depend on what truth is; on the particular way speaking it requires words to relate to those factors (or vice-versa). Further facts can matter at all, and then as they do, only if truth is a notion which demands, case by case, precisely those factors to be arranged in just those ways. Deflationism cannot allow truth to make such demands. (1996: 454; cf. 2000: 230)

The moot question concerns just what 'demands' or 'requirements' truth makes or imposes. Travis points to an answer to this when he writes,

To assess correctly the truth of words which described a ball as being round, one needs to take the right view of what being round would come to [...] But what view is right for this purpose? That is a matter of the sorts of merits truth involves. For if [...] the circumstances of the speaking matter to what truth requires, something about what truth is is needed to make such circumstances matter in one way rather than another, so in the way they do. So there must be something about what truth is which fills that role. (1996: 458) 
The crux of Travis's argument against deflationism rests on the idea that being true involves a kind of 'merit' or value. Critics of deflationism often charge it with failing to incorporate the alleged fact that the notion of truth is intrinsically evaluative, ${ }^{8}$ but Travis's version of this familiar objection, on which I shall focus, is distinctive, insofar as it is based on specifically contextualist considerations; in particular, it concerns how the value of truth relates to a requirement, over and above that of uttering certain words, that has to be met in order to state truth in an utterance on a particular occasion. Hence, to explain how contextualism comes into conflict with deflationism, we must consider Travis's account of 'just what sort of achievement truth is' (1996: 459).

According to Travis, on a given occasion of utterance, subjects form 'perceptions of when to be satisfied with the descriptions they give'. These perceptions are informed by 'a purpose' that the utterance has and 'uses words $[\ldots]$ have in serving it'. Such perceptions 'allow descriptions of things to be the sort of good to us they are' and provide 'the standard' by which to judge utterances of expressions. Since these 'perceptions of occasions are perceptions of what it would be, on them, for a given description to describe truly', Travis continues, this shows that there are 'ingredients in truth' beyond those deflationism allows; most notably, it reveals that it is part of the idea of truth that a description 'must serve all the purposes that must be served $[\ldots]$ on that occasion, by having all the uses it ought in serving them'. Truth demands this. 'Such is our idea of what truth, or stating it, is' (1996: 460-3; cf. 2000: 231).

So, according to Travis, (stating) truth involves a distinctive kind of value; specifically, it is the achievement of having one's words accord with the purposes of 
the occasion, in virtue of which they fit the world. Since deflationism neglects this aspect of truth, it is inadequate.

I think that the deflationist can accept pretty much everything Travis says, but deny that saying it requires appeal to a notion of truth. Consider again (4). Given the circumstances, David's uttering (4) will purport to serve a particular purpose, say, helping Kelly to decide what to have for breakfast. Such considerations lead us to form certain 'perceptions' of David's utterance and thereby contribute to determining that a particular proposition is expressed in it, to its being the case that David says that there is milk in the fridge (understood accordingly). Moreover, given this, it stands to reason that the relevant purpose will be perceived actually to be served by David's utterance if and only if there is milk in the fridge (understood accordingly). Hence, the valuable achievement is one of stating that there is milk in the fridge when there is milk in the fridge.

So, I contend, there is a story in all relevant respects like the one Travis wants to tell, but into which truth does not enter. In this respect, he is wrong to claim that the 'notion of truth cannot be eliminated' from it (2006: 197). ${ }^{9}$ Of course, one can reformulate the account of when the relevant purpose will actually be served by David's utterance in terms of truth, i.e. it will be served if and only it is true that there is milk in the fridge. But this is just an instance of the kind of harmless transition that conforms to the equivalence schema (DS). The deflationist can say that it adds nothing of substance - as shown by the fact that one can happily make the point without the notion of truth. And, of course, the truth-predicate might be indispensable for generalising this story beyond the particular case. In this sense, perhaps, truth-talk cannot be 'eliminated'. But it is precisely the deflationist's point that the truth- 
predicate is primarily a device for making generalisations one could not otherwise make.

Furthermore, one can challenge Travis's claim that the 'demand' to serve 'purposes' belongs to the notion of truth as such. Instead, it is reasonable to suggest that the 'demand' belongs to the notion of making a statement, that it is part of what stating is - the kind of valuable achievement it can be - that it is constitutively purposive. If this is correct, what serving that purpose involves on an occasion or in general can then be explained in the way, compatible with deflationism, sketched above.

This last point connects to the common suggestion that a norm of truth constitutively governs assertion, in the sense that, for any $p$, one correctly asserts that $p$ only if it is true that $p \cdot{ }^{10} \mathrm{~A}$ deflationist could certainly accept this suggestion, viewing it as a generalisation from the particular norms governing specific assertions, such as: one correctly asserts that the pygmy shrew is Britain's smallest mammal only if the pygmy shrew is Britain's smallest mammal; one correctly asserts that the whitetoothed shrew is Britain's smallest mammal only if the white-toothed shrew is Britain's smallest mammal; one correctly asserts that the white-toothed shrew is endangered only if the white-toothed shrew is endangered; and so on indefinitely. ${ }^{11}$ There is, of course, much to say about this proposal but the important point for present purposes is as follows. A deflationist can insist that, if anything, it is assertion rather than truth that is constitutively normative, in the sense that it belongs to the very idea of assertion, not that of truth, that a norm of the sort sketched above applies to acts of asserting. In support, one might note that, in characterising the norm (allegedly) governing assertion, the notion of truth seems to play a role only as a device of generalisation of the sort the deflationist draws our attention to. Moreover, 
assertion is a speech act and so just the sort of thing that can be straightforwardly purposive, where such purpose might generate standards (or 'demands') for subjects to meet.

Of course, if true, contextualism complicates this deflationism-friendly account of assertion somewhat by demonstrating that which particular norm governs a given act of asserting depends on what broader purpose that assertion is in the service of on a particular occasion (answering a query about breakfast supplies, for example). But this serves to supplement the original account, rather than to undermine it.

With this in view, and returning to the issue at hand, consider the following remark by Travis:

Part of this idea [of truth] is that, for a description, and on an occasion [...], there are definite purposes truth demands be served, and uses which truth demands the description have in serving them. (1996: 463)

It is open to the deflationist to reformulate this as follows:

Part of this idea of asserting is that, for a description, and on an occasion, there are definite purposes asserting demands be served, and uses which asserting demands the description have in serving them.

Tellingly, Travis himself wavers on this issue. Recall his remark, 'Such is our idea of what truth, or stating it, is' (my emphasis). Travis seems to treat as interchangeable the claim that it belongs to the concept of truth that making a statement is to serve a purpose and the claim that it belongs to the concept of making a statement that stating is to serve a purpose. But he has certainly not demonstrated his entitlement to do so. Thus, the deflationist can reasonably accept the putative insight about statementmaking but reject the corresponding suggestion about truth. Travis runs the two ideas together again when he writes: 
Can speaking truth really require serving the point, or purpose, of speaking in the terms you do? Truth is a kind of success that a statement, or an assertion, might achieve. The kind of success it is plausibly depends on the kind of thing a statement or assertion is. It is intrinsic to a statement to be understood in terms of a point or purpose it is to serve. It is certainly not then unreasonable that truth should require the statement to serve its point (sufficiently) well. (2000: 232)

Here Travis suggests that making a statement is 'intrinsically' purposeful, that it is the 'kind of thing' that has a point. Hence, making a statement serves its purpose when and only when the statement made is true (a generalisation that deflationism can allow). But Travis treats this as one with the claim that this need to serve a purpose is a consequence of what truth is. The deflationist can refuse to allow this slide.

\section{Oxonian superstition}

Travis challenges the deflationist to offer an account of how truth gets expressed, a challenge that results in a dilemma. But this dilemma, I argued, is not devastating for the deflationist. Elsewhere, Travis levels a quite distinct objection against deflationism, again based on contextualist considerations, which I shall reconstruct and assess in the remainder.

Travis admits that equivalences of the form (DS) are 'banal' (2006: 173). He claims, however, that they invite a 'superstitious' reading, one allegedly discernible in the following remarks by Peter Strawson:

But what could fit more perfectly the fact that it is raining than the statement that it is raining? Of course, statements and facts fit. They were made for each other. If you prise the statements off the world you prise the facts off it too; but the world would be none the poorer. (2004: 152) 
The 'superstition', Travis tells us, involves the idea that true statements (or propositions) and facts are, 'nearly enough, just different versions of the same thing' or 'perfect mirrors of each other'. Call this the Strawsonian view. Travis suggests that this 'superstition' re-emerges in the idea that 'one cannot fail at both' stating truth and stating falsehood 'if one so much as says anything at all' (2006: 173-4). Call this the Dummettian view, since (as Travis notes) Michael Dummett defends it (2001). Travis associates both views with deflationism and thereby charges the latter with superstition.

How exactly these ideas relate is hardly self-evident and Travis does not spell it out. Nonetheless, although Travis nowhere (so far as I can tell) provides it, nor makes reference to it, Dummett presents an argument designed to demonstrate that deflationism is committed to the Dummettian view. Suppose that a person utters ' $p$ ' in certain circumstances but, on the relevant understanding of ' $p$ ' that the circumstances provide, it is neither true that $p$ nor false that $p$. In that case, as Dummett points out (2001: 233), it is false to say, 'It is true that $p$ '. But, ex hypothesi, what ' $p$ ' expresses is not false. Hence, what is expressed by 'It is true that $p$ ' and what is expressed by ' $p$ ' cannot be equivalent. If so, grasp of the equivalence schema (DS) cannot exhaust our grasp of the concept of truth; there are occasions on which we are not disposed to accept an instance of it. Since the deflationist cannot accept this conclusion, she supposedly must accept the Dummettian view. ${ }^{12}$

Where does the Strawsonian fit in? Travis's suggestion that it is one with the Dummettian view is, prima facie, surprising, since it is common to read Strawson as allowing for the possibility of propositions that are neither true nor false in cases of reference-failure (see 2004: 9). ${ }^{13}$ Strawson's actual position notwithstanding, one might be able to demonstrate a link between the Dummettian and Strawsonian views 
as follows. To think, with the Strawsonian, that facts and true statements mirror each other is to think that the 'fit' between them is always perfect, that there are no degrees of fit (see Travis 2006: 180). If a fact and a true statement are two sides of one coin, then the latter cannot do any less than coincide with the former. This in turn suggests that, if a statement does not fit a fact perfectly, it must be false. Hence, as the Dummettian claims, if one says something, one either speaks truly (by mirroring a fact) or falsely (by not mirroring a fact).

Unfortunately, this is too swift. The Strawsonian can maintain that one could fail to state a fact (i.e. a true proposition) without thereby stating a false proposition, by holding that a proposition is false only when its negation is true, and not merely when it fails to be true (i.e. fails to be a fact). Indeed, Travis is himself sympathetic to the suggestion that 'being false is not in general the same thing as being not true' (1994: 168).

Alternatively, one might connect the Strawsonian view to the Dummettian via the latter's (alleged) link to deflationism. Perhaps deflationism is committed to the Strawsonian view for the following reason. If true statements and facts are not equivalents, there would be something substantive to say, of the sort deflationism does not allow, about how exactly they correspond and the degrees to which they might do so. ${ }^{14}$ In this way, the Strawsonian view might hook up with deflationism, and with it the Dummettian view.

On behalf of Travis, I have put together a case for thinking that the deflationist, Strawsonian and Dummettian are bedfellows. However, that case is far from watertight. Wolfgang Künne (2003), ${ }^{15}$ for example, advances a version of deflationism while resisting the identification of true propositions and facts and allowing for the possibility of truth-value gaps. I shall not enter into the details of 
Künne's distinctive proposal here since, as I shall now argue, even if the deflationist is forced to take sides with the Dummettian and the Strawsonian, Travis does not provide any specifically contextualist considerations that show their union to be a troubled one.

Initially, Travis focuses on the Strawsonian view, suggesting that it is committed to the denial of contextualism. Suppose, contra contextualism, that for a given sentence there is a proposition one expresses or a statement one makes in uttering it and, furthermore, that there is 'only one such statement. It is the one one always makes' with it. If (and presumably, though Travis does not say as much, only if) this is correct, there 'could be no room for any fit between statements and that which they represent as so except for perfect or none' (2006: 181-3). Since, however, contextualism shows the supposition to be false, the Strawsonian view has to go, and with it deflationism (and the Dummettian view).

Note however, that, despite Travis's suggestion to the contrary, Strawson appears entirely sympathetic to contextualism, insisting that 'the question of whether a sentence or expression is significant or not has nothing to do with the question of whether the sentence, uttered on a particular occasion, is, on that occasion, being used to make a true-or-false assertion' (2004: 7). Moreover, Strawson's sympathy is well-founded, since the Strawsonian view is entirely compatible with contextualism. The Strawsonian claims only that, when a statement is true, it 'fits' a fact perfectly; it is officially silent about how such a statement comes to be made. It might well be, with contextualism, that there is no one-to-one correlation between sentences and the statements one makes in uttering them, and so no one-to-one correlation between sentences and facts, but rather that the same sentence might be used to make different statements, and so fit perfectly different facts, on different occasions. 
Consider instead the reasons Travis offers for thinking that the Dummettian view is incompatible with contextualism. Since, as explained above, there is some (inconclusive) reason to think that the Dummettian view is bound up with the Strawsonian, and in turn with deflationism, this might provide the missing argument. Travis asks,

If I speak of the green hills along the Minho, and many of them turn out to have houses on them (the houses breaking the green of the surrounding foliage), are they green hills or not? [...] Is the answer to that contained (and, if so, uniquely) in the understanding my statement bears tout court? There is no good reason to think so. (2006: 182)

Here, Travis opposes the Dummettian view. It might be the case, he claims, that a statement is made on a given occasion, a particular proposition expressed, and yet that proposition, bearing the particular understanding it does, is neither true nor false.

Note that this suggestion must be distinguished from the similar-sounding contextualist thought that it is possible for a meaningful sentence to be uttered and yet for no statement to be made. This might occur when, given the circumstances, using those words serves no purpose whatsoever. The possibility of such a scenario is not in conflict with deflationism, since it is one in which no proposition (that might provide an instance of (DS)) is expressed. The claim under consideration is, rather, that the circumstances might contribute to determining that a particular statement is made and yet, given the way the world is, that statement bears no truth-value. Travis offers the following illustration:

We are sitting in Jones' living room with Jones when suddenly, and quite unexpectedly, he dies. A moment later there is a knock at the door. We open and are asked, 'Is Jones home?' 
According to Travis, what one would say if one were to answer, 'Jones is at home,' would be neither true nor false:

There are reasons for counting Jones as at home. There he is in his chair, for example. There are reasons for counting him as not at home. He is dead. One might say that dead people are not—certainly do not live — anywhere, a forteriori not at home. So, 'neither the reasons for, nor those against, counting Jones as at home outweigh their conflicting counterparts' (1994: 169-70). As explained above, if Travis is justified in his opposition to the Dummettian view, deflationism (and maybe the Strawsonian view) might be in trouble.

Several considerations might support Travis's anti-Dummettian claim; the present issue is whether Travis provides specifically contextualist considerations that constitute such support, and thereby undermine deflationism. ${ }^{16}$ Travis certainly thinks so, describing contextualism as the 'key' or 'fundamental' point with respect to the issue (1994: 167, 174). But, once more, it is not apparent why this should be so. The central claim of contextualism is that what proposition is expressed in an utterance is partially determined by the surrounding circumstances. The further claim that the proposition thereby expressed might be neither true nor false is a distinct and putatively additional commitment. Travis needs to show that, for the contextualist, this further commitment is not optional.

Accordingly, Travis offers a distinctively contextualist explanation of how a proposition might fail to possess a truth-value. Given contextualism, he says, It is $[\ldots]$ a contingent matter what understanding [words'] surroundings confer on them. But it is also contingent whether that understanding is refined enough so that on it words would be true (or false). (1994: 176; cf. 2006: 187)

His suggestion is that, on an occasion of utterance, the circumstances might determine that a proposition is expressed but one not 'refined' enough for it to count, given how 
the world is, as true or false. Although the context provides a way of understanding what is said, that way might in turn be understood or 'refined' in various ways, some true and some false, and the context does not choose among them. What is said, the proposition expressed, lacks a truth-value when it is true on some of these refinements but false on as many others. So, there appears to be a way of developing the contextualist account of what words come to express on a given occasion of utterance that brings it into conflict with the Dummettian view and thereby deflationism (and the Strawsonian view).

While it is certainly true that a contextualist could provide some such explanation as to how what is expressed in an utterance might fail to possess a truthvalue, it seems equally possible for her to hold on to the Dummettian view by insisting that, while context determines which proposition is expressed in an utterance, whatever proposition is in fact expressed the world will be such as to render it either true or false. ${ }^{17}$ This would be to say that, given a circumstance of utterance, the proposition expressed is always sufficiently refined for it to have a truth-value. Moreover, on reflection, there appear to be some - if not decisive-reason for contextualists to maintain the Dummettian line. Recall that, for the contextualist, what proposition is expressed by certain words is determined in part by the purpose uttering them is perceived to be in the service of, and specifically by how subjects should expect the description offered to enable them to deal with their surroundings. This suggests that, for the contextualist, it is precisely the role of circumstances and in particular the purpose of utterance to provide a 'refined' way of understanding what is thereby expressed. Indeed, one might say, if the purpose is not definite enough to provide some definite way of understanding what is expressed - such that it counts as either true or false - then it fails to determine that anything at all is expressed (even if 
it appears to do so). ${ }^{18}$ In such a case, one might say, the circumstances are just not doing their job.

This might seem a counterintuitive position for the contextualist to hold, since, according to it, there might be instances in which it seems to all involved that something is being expressed in an utterance when, by the lights of this account, nothing is. This phenomenological point is, of course, hardly decisive. There are a number of strategies available to the contextualist for dealing with it, perhaps leaning on work done in other areas of philosophy that recognise the possibility that, despite appearances, meaningful sentences can fail to express anything (for example, cases of reference-failure). Whatever the prospects of such strategies, contextualism is already committed to the possibility of meaningful words not expressing a proposition in light of the circumstances (as discussed above). In this respect, Travis and the Dummettian are all on fours - the phenomenological point does not choose between them. In any event, as stressed at the outset, it is not my aim here to defend contextualism, but to consider its consequences. The important point for present purposes is that, while a contextualist might, with Travis, reject the Dummettian view, there are some contextualist considerations that speak against doing so.

Indeed, if one reflects on one of the motivations for embracing contextualism, it would seem that it should lead one to a version that embraces the Dummettian view. Recall Travis's argument, prompted by Wittgenstein's remarks on rule-following. Given that any given representation 'admits of interpretations', one can avoid the intolerable conclusion that such a representation cannot so much as say anything only by allowing that the context determines that a certain interpretation is appropriate. Parity of reasoning speaks against rejection of the Dummettian view. For Travis, in the case of truth-value gaps, context might determine that a sign bears a certain 
understanding — as saying something. But what it says, so understood, is neither true nor false, since it, in turn, admits of different understandings — as saying various things — some true and as many false. Does this not equally threaten the idea that there is anything that counts as understanding the sign — that is says anything —at all? If, as Travis suggests, in order for a sign so much as to say something, context is needed to determine that it is to be understood in a certain way, then surely this applies all the way down. In that case, it would appear that certain of the considerations that lend support to contextualism also support the Dummettian view. The contextualist's account of why the circumstances of utterance need to be taken into consideration and the job they are supposed to do runs counter to Travis's explanation of how an utterance might express an unrefined proposition that is neither true nor false.

I do not take myself to have conclusively established that, if contextualism is true, uttered expressions should be understood in such a way as to be assigned a truthvalue (or not at all). The claim is only that there is some reason for a contextualist to think so. At best, the balance is tipped in favour of the Dummettian contextualist. At worst, there is a deadlock. Either way, Travis has not shown that contextualism rules out deflationism by ruling out the Dummettian view.

Having forged, on Travis's behalf, (tenuous) connections between the Strawsonian view, the Dummettian view and deflationism, I argued, contra Travis, that contextualism does not immediately rule out the Strawsonian view, and with it deflationism. Next, I considered whether one might proceed via the Dummettian view instead but suggested that Travis's argument against it, based again on contextualism, is inconclusive. Hence, it remains to be shown that, in light of contextualism, any element of the above package is 'superstitious'. 


\section{Conclusion}

Crudely put, deflationism tells us there is not much to say about what truth is. Equally crudely, Travis aims to show that, given contextualism, there is in fact rather a lot to say about what truth is. I hope to have shown that his arguments for this 'inflationary' claim are not compelling. Of course, there might be other considerations that reveal deflationism to be an inadequate account of truth, but Travis has given us no reason to think that contextualism in particular is its undoing.

One reason for contextualism's importance is that it serves to remind us that language-use is situated, that language-users are embodied agents, that talk is embedded in concrete circumstances, and so that to understand what it is to express something in words one must understand how utterances are located in the milieu of human activity, with its peculiar purposes, histories and values. Although deflationism is silent on such considerations, this does not mean that it renounces them. A suitably inflated view of what stating truth requires is compatible with a suitably deflated view of what truth is.

\section{References}

Bar-On, D. and Simmons, K. 2006: Deflationism. The Oxford Handbook of Philosophy of Language, ed. E. Lepore and B. Smith. Oxford: Oxford University Press.

Borg, E. 2009: Meaning and context: a survey of a contemporary debate. The Later Wittgenstein on Language, ed. D. Whiting. Basingstoke: Palgrave.

Brandom, R. 1994: Making it Explicit: Reasoning, Representing and Discursive Commitment. Cambridge, Massachusetts: Harvard University Press. 
Cappelen, H. and Lepore, E. 2005: Insensitive Semantics: a Defense of Semantic Minimalism and Speech Act Pluralism. Oxford: Blackwell.

Dodd, J. 2000: An Identity Theory of Truth. Basingstoke: Palgrave.

Dummett, M. 2001: Truth. The Nature of Truth, ed. M. Lynch. Cambridge, Massachusetts: MIT Press.

Field, H. 2001: Truth and the Absence of Fact. Oxford: Oxford University Press.

Horwich, P. 1990: Truth. Oxford: Oxford University Press.

— 2005: Reflections on Meaning. Oxford: Oxford University Press.

Künne, W. 2003: Conceptions of Truth. Oxford: Oxford University Press.

Lynch, M. 2004: Minimalism and the value of truth. Philosophical Quarterly 54: 497517.

Simmons, H. 1997: Circumstances and the truth of words. Mind 106: 116-117.

Strawson, P. 2004: Logico-Linguistic Papers, $2^{\text {nd }}$ ed. Aldershot: Ashgate.

Travis, C. 1989: The Uses of Sense: Wittgenstein's Philosophy of Language. Oxford: Oxford University Press.

- 1994: On being truth-valued. Foundations of Speech Act Theory, ed. S. Tsohatzidis. London: Routledge.

- 1996: Meaning's role in truth. Mind 105: 451-466.

- 1997: Pragmatics. A Companion to Philosophy of Language, ed. B. Hale and C. Wright. Oxford: Blackwell.

- 2000: Unshadowed Thought: Representation in Thought and Language. Cambridge, Massachusetts: Harvard University Press.

- 2006: Thought's Footing: a Theme in Wittgenstein's Philosophical Investigations. Oxford: Oxford University Press.

Whiting, D. Forthcoming: Should I believe the truth? Dialectica. 
Williams, M. 2004: Context, meaning, and truth. Philosophical Studies 117: 107-129.

Williamson, T. 2002: Knowledge and its Limits. Oxford: Oxford University Press.

Wittgenstein, L. 1958: Philosophical Investigations, rev. ed., ed. G. E. M. Anscombe and R. Rhees. Oxford: Blackwell.

Wright, C. 1992: Truth and Objectivity. Cambridge, Massachusetts: Harvard University Press.

\section{Notes}

${ }^{*}$ I am grateful to two referees for this journal for their comments on an earlier version of this paper. I have not been able to address all the issues those comments raise but hope to do so elsewhere.

${ }^{1}$ I shall focus on Horwich's version of deflationism, primarily because Travis does so, though no doubt one could reformulate its discussion using the terms with which other deflationists operate (e.g. Field 2001).

Note that Horwich typically describes his account of truth as 'minimalist' rather than 'deflationist'. I shall stick to the latter term as Wright (1992) advances a resolutely non-deflationary approach to truth under the banner of 'minimalism'. ${ }^{2}$ For a wide-ranging assessment of contextualism, not focused on the issue of its relation to deflationism, see Cappelen and Lepore 2005.

${ }^{3}$ For a critical overview of many of the challenges to deflationism, not including the contextualist's, see Bar-On and Simmons 2006.

${ }^{4}$ I am adapting Travis's example (1989: 18-19).

${ }^{5}$ I shall not take a stand here on the merits of this reading of Wittgenstein. 
${ }^{6}$ Cf. Williams 2004: 123. Surprisingly, Travis (2006: 195) offers a very similar vindication of Wittgenstein's apparent readiness to advance a version of deflationism (1958: §126).

${ }^{7}$ Deflationists typically offer use-based or conceptual role accounts meaning (see, e.g., Brandom 1994; Field 2001; Horwich 2005: ch. 2).

${ }^{8}$ For a classic statement of this objection, see Dummett 2001. For a reply, see

Horwich 2005: ch. 5. For a sustained critical discussion of the issue, see Lynch 2004.

${ }^{9}$ Williams (2004: 125-126) makes a similar point, though he neither approaches nor develops it in quite the way I do.

${ }^{10}$ Williamson (2002: ch. 11) argues that knowledge is a constitutive norm of assertion, in the sense that (roughly), for any $p$, one correctly asserts that $p$ only if one knows that $p$. Since that one knows that $p$ entails that it is true that $p$, this formulation of the norm of assertion is not in competition with that which I provide in the main text. ${ }^{11}$ For a more detailed elaboration and discussion of this deflationary proposal, see Horwich 2005: ch. 5. Horwich discusses the norm of truth as it applies to belief, though he views believing as a mental or internal analogue of asserting. For further discussion of the idea of a norm of truth and how one might formulate such a norm, see Whiting forthcoming.

${ }^{12}$ Accordingly, Horwich (1990: 80ff) is sympathetic to the Dummettian view. Dummett, of course, is no fan of deflationism (see 2001).

${ }^{13}$ Admittedly there are some passages in which Strawson suggests that, in cases of reference-failure, no proposition is expressed at all. But this hardly supports Travis's case.

${ }^{14}$ Accordingly, Brandom (1994: 327ff) and Horwich (1990: 112ff) are sympathetic to the Strawsonian view. For a sustained discussion of the Strawsonian view and its 
relation to deflationism, see Dodd 2000. For criticism of the idea that facts are true propositions, see Künne 2003: 6-12. Note, however, that this criticism makes no contextualist assumptions.

${ }^{15}$ Künne prefers to describe his conception of truth as 'modest'. For his reasons, see 2003: 19-20.

${ }^{16}$ Travis appears to suggest that, if one accepts the possibility of truth-value gaps, one should accept contextualism in order to avoid an otherwise fatal contradiction (see 1994: 171, 183; cf. Horwich 1990: 80; cp. Künne 2003: 331-333). However, the present issue concerns whether the reverse holds, that is, whether contextualists must accept the possibility of truth-value gaps.

${ }^{17}$ Of course, one might simply stipulate that contextualism is, not simply the view that a given expression might, depending on the circumstances, be understood to express any number of different things, but the view that what is expressed in those circumstances might in turn be understood in any number of different ways. The question then becomes whether the considerations I sketched in $\S 2$ - the arguments from shifting contexts and from rule-following — support contextualism, so understood, or only some weaker variant. The remarks that follow may then be taken to suggest the latter.

For a critical survey of the many different views according to which what is expressed in an utterance is a context-sensitive matter, see Borg 2009.

${ }^{18}$ Surprisingly, Travis seems sympathetic to a version of this idea (1994: 180ff). 